\title{
Cross-Polar Nomalies
}

\author{
Daniel Büring \\ $U C L A$
}

\section{Cross-Polar Anomalies}

It has long been observed that comparatives that pair a positive adjective $\left(\mathrm{A}^{+}\right.$,

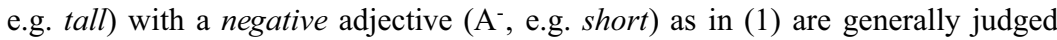
unacceptable (Bierwisch 1989, Hale 1970, Seuren 1978), a phenomenon dubbed cross-polar anomaly in Kennedy (2001):

$$
\text { * } \mathrm{A}^{+} \text {-er than } \mathrm{A}^{-/ *} \mathrm{~A}^{-} \text {-er than } \mathrm{A}^{+}
$$

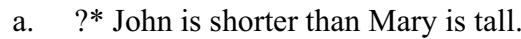

b. * Mary is taller than John is short.

Generally, explanations for the anomaly of these examples are based on the intuition that degrees of 'tallness' and degrees of 'shortness' are of a different nature and hence cannot be compared. Note that this is not obvious, since pre-theoretically one may think that tallness and shortness are different words for the same measurement, roughly: vertical spacial extension (or simply: height). Kennedy (2001) (following Rullmann 1995, Seuren 1978, 1984, von Stechow 1984: a.o.) provides a very elegant implementation of this idea: $\mathrm{An}^{+}$like tall relates an individual to a positive length, an $\mathrm{A}^{-}$like short to a negative one, where a positive length is an interval (a set of degrees) that starts just above 0 and extends up to an object's height (length/width/richness...), whereas a negative length is an interval that starts just above an object's height (length/width/richness ...) and goes up to $\infty$.

Whatever the semantics of (mo)re, it cannot compare a positive with a negative length (in this technical sense), hence the anomaly of (1). On the other hand, since, say, tallness and shortness 'live' on the same scale and are logically related to an object's height, the usual entailment patterns (A is taller than B iff B is shorter than A etc.) follow under any reasonable semantics for relational measure constructions.

\section{Cross-Polar Nomalies}

Against this background it is surprising that examples like (2) are perfectly wellformed and interpretable (for similar examples see Faller 1998), cf. figures 1-3:

Thanks to Jessica Rett for discussion, to Roger Schwarzschild for sharing his wisdom and notes on comparatives, and to the audiences at SALT and UCLA's syntax semantics seminar for comments and discussion. 


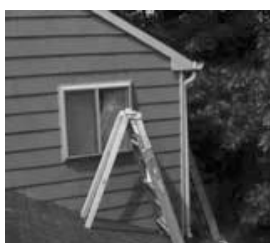

Figure 1: The ladder was shorter than the house was high.
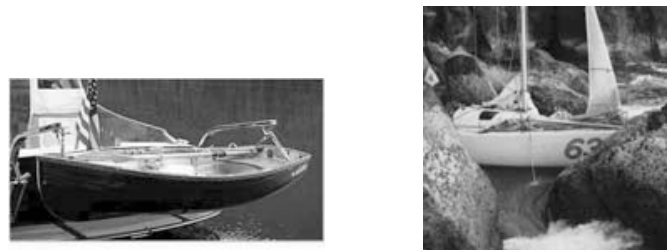

Figure 2: Your dinghy Figure 3: Sadly, the passage should be shorter than between the rocks was naryour boat is wide. rower than the boat was long.

(2) a. Unfortunately, the ladder was shorter than the house was high.

b. My yacht is shorter than yours is wide.

c. Your dinghy should be shorter than your boat is wide (otherwise you'll bump into the bulkhead all the time).

Aenictogiton sulcatus Santschi: Scape reaching the posterior quarter of the eyes. Funiculus narrowing medially, segments 3-5 narrower than long. ${ }^{1}$

These examples clearly involve comparison between an $\mathrm{A}^{+}$and an $\mathrm{A}^{-}$(they are 'cross-polar'), but fail to invoke any judgement of anomaly, which is why I propose to christen them cross-polar nomalies.

The challenge is to come up with a semantics that allows for comparison of positive and negative lengths in cross-polar nomalies like (2) and (3) while still ruling out regular cross-polar anomalies as in (1) above. This paper attempts to meet that challenge.

\subsection{Delimiting the Phenomenon}

What sets cross-polar nomalies apart from cross-polar anomalies? Crucially, all cross-polar anomalies involve comparison of an adjective with its direct antonym. And indeed, a parallel example to (2a) yields a bona fide anomaly:

$$
\text { ?* Unfortunately, the hose is shorter than the ladder is long. }
$$

In contrasts, the acceptable examples all involve comparing a negative measurement of extension in one dimension (say, shortness) with a negative measurement of extension in another (say, height). That is, they involve cross-polar, but nonantonymous pairs like short-high, short-wide, narrow-long, as opposed to crosspolar antonyms such as short-long, narrow-wide, low-high etc. ${ }^{2}$

\footnotetext{
${ }^{1}$ Santschi, F. 1919. Fourmis nouvelles du Congo. Revue de Zoologie Africaine 6: 243-250. Translated at http://antbase.org/ants/africa/clog3.htm.

${ }^{2}$ It is important here to distinguish scale, polarity and dimension: tall, high, long, wide, deep etc. all map an object to a positive measurement on the same scale, call it spacial extent. They measure
} 
A second necessary condition for cross-polar nomalies is that the $\mathrm{A}^{-}$be in the main clause, while the $\mathrm{A}^{+}$has to be in the than-clause. If we invert this configuration, the examples become unacceptable again:

* Unfortunately, the house is higher than the ladder is short.

We may sloppily refer to examples like (5) as 'inverse cross-polar nomalies', since like cross-polar nomalies they involve non-antonymous As of opposite polarity, but have the polarities inverted vis-a-vis 'normal' cross-polar nomalies (I say 'sloppily' though, because these are crucially not 'normal', but abnormal, i.e. unacceptable). The empirical pattern is summarized below:

Cross-Polar Anomaly:

$* A^{+}$-er than $A^{-/ *} A^{-}$-er than $A^{+} \quad$ if $\mathrm{A}^{-}$and $\mathrm{A}^{+}$are direct antonyms

Cross-Polar Nomaly:

$A^{-}$-er than $A^{+}$

is ok if $\mathrm{A}^{-}$and $\mathrm{A}^{+}$are not direct antonyms

Inverse Cross-Polar Nomaly:

$* A^{+}$-er than $A^{-}$

even if $\mathrm{A}^{-}$and $\mathrm{A}^{+}$are not direct antonyms

\subsection{Structure of the Paper}

In Section 3 I will informally preview my proposal for analyzing cross-polar nomalies, followed by a formal implementation in Section 4. In Section 5 I sketch what I consider a plausible and attractive alternative analysis of the phenomenon, which yields overall identical predictions, but turns out to differ on a rather subtle subset of the relevant data, which I explore in depth in Section 6. My conclusion will be that the analysis sketched first is empirically more adequate than the alternative brought up later.

different dimensions of a given object (length, height, width etc.), though, and accordingly have different domains (a person probably doesn't have a length or depth, a lake doesn't have a height etc.). But if a given object is exactly as high as it is wide, its height and width are exactly the same formal object (a set of degrees of spacial extension starting at the bottom of the scale and extending to the object's height/width). The same is true mutatis mutandis for short, low, narrow, shallow etc. These, too, map objects onto intervals on the scale of spacial extension, but all of these are intervals that start at a given point and go upwards to the upper end of the scale. Since spatial extent is the only scale I know of that has measurements in different dimensions mapped onto it, all examples in this paper involve adjectives that measure spatial extent. 


\section{Analysis}

\subsection{The more to less Metamorphosis}

At the heart of my proposal is the idea that cross-polar nomalies are interpreted as less $A+$ rather than more $A$-. For example, (2a), repeated in (6a), is interpreted as $(6 b)$ :

(6) a. Unfortunately, the ladder was shorter than the house was high.

b. the ladder is less long than HOW the house is high

Note that (6b) compares two positive degrees, and hence no anomaly is predicted.

Why is this interpretation possible? Building on the proposals in Rullmann (1995) and, in particular, Heim (2006a), I assume that a negative A like short is interpreted as the (degree) negation of its positive counter-part: $s$ ort $=$ LITTLE long.

Furthermore, a less-comparative as in (6) is the combination of comparative

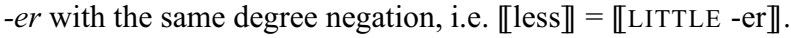

Cross-polar nomalies result from the option of interpreting [LITTLE long] -er as [LITTLE-er] long. I believe that this (re-)interpretation of comparative negative As (as well as less-comparatives) can be observed independently (cf. Büring 2007), and hence that cross-polar nomalies are an additional piece of evidence for this option.

\subsection{Regular Anomalies}

This proposal raises the question why cross-polar anomalies are unacceptable. Why can't e.g. (4), repeated in (7a), receive the logical form in (7b)?

(7) a. ?* Unfortunately, the hose is shorter than the ladder is long.

b. the hose is LITTLE-er long than HOW the ladder is long

I submit that (7b) is indeed a possible structure, but that it is pronounced as either $(8 a)$ or $(8 b)$, rather than $(7 a)$ :

(8) a. The hose is less long than the ladder (is).

b. The hose is shorter than the ladder (is).

c. the hose is LITTLE-er long than HOW the ladder is tong 
The relevant construals of (8a) and (8b) have the same logical form, (8c). (8c), I submit, is preferred over (7b) because ellipsis of the entire AP in the than-clause as in (8c) is preferred over deletion of only the degree morphology in the than-clause (indicated by HOW) as in (7b) (cf. Max Elide, Takahashi and Fox 2005). Another way of saying this is that comparative deletion is preferred over comparative subdeletion, where possible. ${ }^{3}$

\subsection{Nomalies}

Returning to cross-polar nomalies, comparative deletion (i.e. ellipsis of the $\mathrm{A}$ in the than-clause) is not an option here since the two A's - even factoring out LITTLE - are not identical. Their logical form has to be $(9 a)$, rather than $(9 b)$ or $(9 c)$ :

(9) a. the ladder was LITTLE-er long than HOW the house was high

b. the ladder was LITTLE-er long than HOW the house was high

c. the ladder was LITTLE-er long than HOW the house was long

(9b) is simply not a well-formed ellipsis: long can't license ellipsis of high. (9c) is a well-formed structure, but doesn't compete with (9a). (9c) would be pronounced (10):

(10) ??Unfortunately, the ladder was shorter than the house was.

(10) is degraded, because long is not defined with houses. What's important, though, is that (10) doesn't mean the same as the cross-polar anomaly the ladder was shorter than the house was high (since it involves different As). Even in cases where comparative deletion is well-formed, as in (10), no blocking occurs, since the two forms have different lexical material as well as different interpretations, and hence are not competing:

(11) a. My yacht is shorter than yours is wide.

b. My yacht is shorter than yours.

In short, cross-polar nomalies are fine because the non-antonymous As in them do not license comparative deletion the way antonyms can, and hence no blocking occurs.

\subsection{Inverse Cross-Polar Nomalies}

Finally, the explanation for the unacceptability of inverse cross-polar nomalies like (5), repeated in (12) is straightforward:

(12) * Unfortunately, the house is higher than the ladder is short.

\footnotetext{
${ }^{3} \mathrm{I}$ also believe that interpreting $A^{-}$-er as 'less $\mathrm{A}^{+}$' is a slightly dispreferred option in general, further penalizing (7b) as well as ( $8 b)$. The data discussed in this paper, however, do not lend themselves to arguing for this preference in the way those discussed in Büring (2007) do.
} 
The LF for (12) is (13):

(13) the house is MORE high [ than HOW the ladder is LITTLE-long ]

LITTLE and MORE are in separate clauses here; there is thus no way to re-interpret (13) as (14):

(14) the house is LITTLE-er high [ than HOW the ladder is long ]

\section{Implementation}

For the sake if concreteness, I assume the constituent structures in (15)-(18):

(15)

longer than

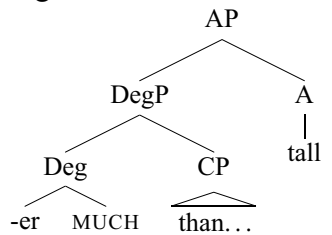

(17)

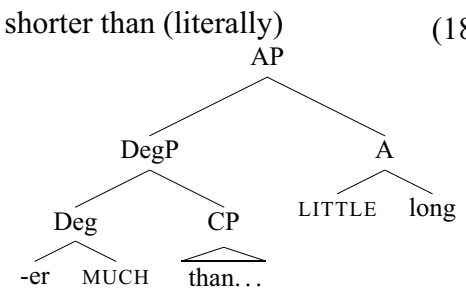

(16) less long than

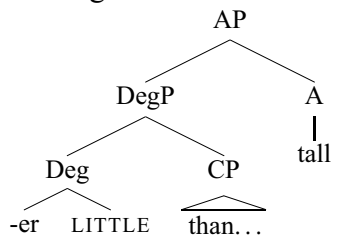

18) shorter than (alt.)

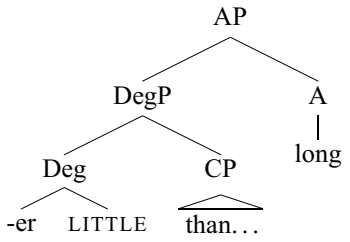

I adopt an ontology that includes individuals of type $d$, degree points, as well as various orderings among disjoint subsets of these. Since the only degree points of interest in this paper are degrees of spacial extent, we can think of the ontology as containing only degrees of spacial extent and one ordering $\leq$ on them:

(19) types

a. $\quad \mathrm{d}$ : the type of degree points (comes with an ordering $\leq$ )

b. $i$ : the type of degree intervals

The type $i$ of degree intervals has as its domain a subset of $\mathrm{D}_{\langle\mathrm{d}, \mathrm{t}\rangle}$, namely non-empty and convex subsets of $D_{d}$ :

(20) for any $i \subseteq D_{d}, i \in D_{i}$ iff $i \neq \emptyset$ and $\forall d, d^{\prime}, d^{\prime \prime}$, if $d, d^{\prime \prime} \in i$, and $d \leq d^{\prime} \leq d^{\prime \prime}$, then $d^{\prime} \in i$

Representative lexical meanings are given in (21): 
(21) a. 【tall/high $=\lambda d_{d} \cdot \lambda x_{e} \cdot d \leq H E I G H T(x)$

b. $\llbracket \mathrm{MUCH} \rrbracket=\lambda i_{i} . i$

c. $\llbracket$-er $\rrbracket=\lambda m_{i, i} \cdot \lambda i_{i} \cdot \lambda i_{i}^{\prime} \cdot m(i) \subset m\left(i^{\prime}\right)$

d. 【LITTLE $\rrbracket=\lambda i_{i} \cdot \lambda d_{d} \cdot i(d)=0$

It can easily be seen that, given these assumptions, (22) holds:

(22) $\llbracket$ short $\rrbracket=\llbracket L I T T L E$ high $\rrbracket$

$$
\begin{array}{ll}
= & {\left[\lambda i_{i} \cdot \lambda d_{d} \cdot i(d)=0\right]\left(\lambda d_{d} \cdot \lambda x_{e} \cdot d \leq H E I G H T(x)\right)} \\
= & \lambda x_{e} \cdot \lambda d_{d} \cdot\left[\lambda d^{\prime} \cdot d^{\prime} \leq H E I G H T(x)\right](d)=0 \quad \text { (see discussion below) } \\
= & \lambda x_{e} \cdot \lambda d_{d} \cdot d \leq H E I G H T(x)=0 \\
= & \lambda x_{e} \cdot \lambda d_{d} \cdot d \not \leq H E I G H T(x) \\
= & \lambda x_{e} \cdot \lambda d_{d} \cdot \operatorname{HEIGHT}(x)<d
\end{array}
$$

According to (21c), $\mathrm{x}$ is [MUCH-A]-er than B if x's A-ness is a proper super-interval of y's A-ness. It should be noted that $\mathrm{MUCH}$ contributes, as it were, little to the meaning of a plain comparative: It simply denotes the identity function on intervals, which, by the semantics of $-e r$ in (21c) is applied to both its arguments before the comparison by $\subset$. This is different if -er combines with LITTLE instead of MUCH: Now the interval obtained from the main clause as well as the interval obtained from the than-clause are inverted (by the meaning of LITTLE) before $\subset$ applies. So $x$ is e.g. LITTLE-er long than $y$, if x's LITTLE-longness is a superset of y's LITTLElongness, that is, if the set of intervals above x's length are a superset of those above y's length, i.e. if $\mathrm{x}$ is shorter than $\mathrm{y}$. Put differently, LiTTLE turns a morecomparative into a less-comparative by inverting both intervals compared.

Though not much hinges on it, on the semantics given the comparative DegP wants to combine with an interval-denoting phrase (type $i$, or $\langle d, t>$ ), while the A denotes a function from a degree to a set of individuals (type $<d,<e, t>>$ ). For simplicity I assume, e.g. in (22), a composition rule that allows them to combine directly as in (23a), yielding $\lambda x_{e} \cdot \llbracket \mathrm{DegP} \rrbracket(\lambda d . \llbracket \mathrm{A} \rrbracket(d)(x))$. 
The same rule is used to combine LITTLE with an A. In its general form, this is the rule that allows e.g. a generalized quantifier to combine with a transitive verb meaning ${ }^{4}$, and so, unsurprisingly, the same result can be achieved using quantifier raising (of DegP) and function application only, cf. (23b):

(23) the ladder is longer...

a.

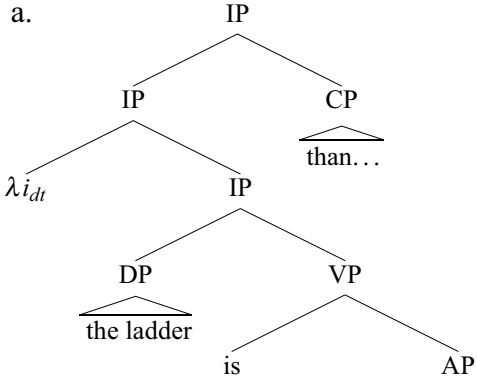

b.

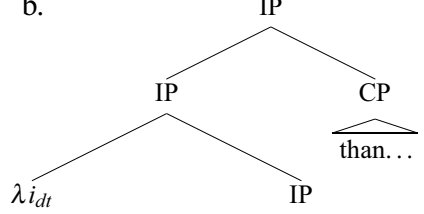

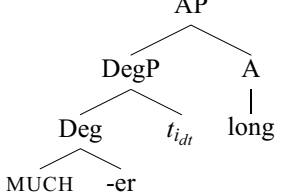

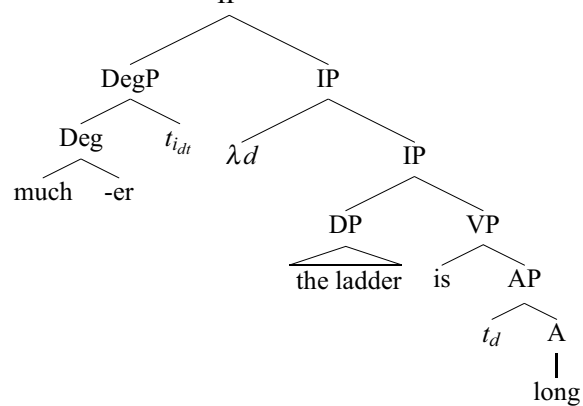

The various versions of the main clause can now be obtained by substituting any of the APs in (16)-(18) for the AP in the trees in (23).

].VP ].IP ].IP

The than-clause simply denotes an interval, which we get by moving a semantically vacuous degree argument, called HOW here, to SpecC:

$$
\text { than the house is high }
$$

${ }^{4}$ A generalized version is given in (i) - cf. also the argument saturation rule in Büring (2004), sec. 3.2.1, and the fully generalized $\kappa$-combinator in Büring (2005), sec.4.5.3:

(i) if $\mathrm{A}$ is of type $\left\langle\tau_{1},\left\langle\tau_{2}, \mathrm{t}\right\rangle\right\rangle$ (with $\tau_{1 / 2}$ any type) and the domain of $\mathrm{B}$ is $D_{\left.<\tau_{1}, t\right\rangle}$, then $\llbracket \mathrm{A} \mathrm{B} \rrbracket=\llbracket \mathrm{B} \mathrm{A} \rrbracket={ }_{\text {def }} \lambda v_{\tau_{2}} \cdot \llbracket \mathrm{B} \rrbracket\left(\lambda v_{\tau_{1}}^{\prime} \cdot \llbracket \mathrm{A} \rrbracket\left(v^{\prime}\right)(v)\right)$ 


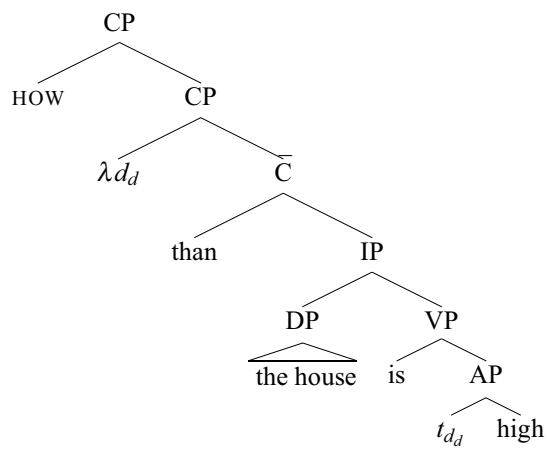

This concludes my presentation of the official proposal for analyzing cross-polar nomalies. I will now sketch a slight variant on this analysis; my final conclusion, however, will be that the analysis given in this section is the empirically more accurate one.

\section{An Alternative}

Returning to our perennial example of a cross-polar nomaly, could it have the $\mathrm{LF}(25 \mathrm{~b})$ rather than our earlier proposal, $(25 \mathrm{a}){ }^{5}$

(25) Unfortunately, the ladder is shorter than the house is high.

a. as per above sections: the ladder is LITTLE-er long than the house is high

b. alternative: the ladder is MORE LITTLE-long than the house is EITTLEhigh

Unlike our earlier (25a), (25b) has (25) denote an ordinary more-comparative of a negative adjective. There is a second LITTLE in the than-clause, which turns a height-interval into a shortness-interval, resolving the cross-polar mismatch. The reason LITTLE high in the than-clause is pronounced as high rather than low is that LITTLE is elided under identity with LITTLE in the main clause (comparative subdeletion), leaving high to be pronounced by itself. ${ }^{6}$

$\left[t_{d}\right.$

We can re-cast much of the analysis in Sections 3 and 4 above on this alternative view: cross-polar anomalies are ruled out because rather than just eliding LITTLE, one has to elide the larger LITTLE $A$ under identity with the parallel AP in the main clause. For example in ? ${ }^{*}$ Mary is shorter than John is tall, shorter (=MORE LITTLE-long) forces comparative deletion of EITTLE-tong in the

\footnotetext{
${ }^{5}$ An analysis along these lines was also proposed by an anonymous SALT reviewer.

${ }^{6}$ The version without ellipsis, The ladder is shorter than the house is low is probably acceptable, and certainly interpretable (both intuitively and formally). I'm inclined to think that it's less than perfect acceptability is due to a preference for comparative subdeletion over no deletion at all.
} 
than clause (yielding Mary is shorter than John (is)), rather than just subdeletion as in ŁTTLE-long.

Cross-polar nomalies don't show this effect since deletion of LITTLE $A^{+}$ (e.g. LITTLE high) is not licensed by LITTLE long in the main clause, hence comparative subdeletion is the biggest ellipsis possible.

Inverse cross-polar nomalies (*Your yachts is wider than mine is short) are impossible because for that, short (=LITTLE long) in the than-clause would have to license ellipsis of LITTLE in (MORE EITTLE-wide) in the main clause. But this kind of ellipsis in the main clause is generally completely impossible:

*You rope is more than mine is long.

So we see that this alternative covers the basic cases in the same way as our first proposal. In its favor we can adduce that it doesn't require interpreting more $A^{-}$as less $A^{+}$, sparing us in turn any headaches about the syntax-morphology interface, and that its use of the ellipsis preference to rule out cross-polar anomalies is perhaps a little simpler than under the original proposal. But are there empirical ways to tease them apart?

\section{Choosing}

It turns out that the two analyses, though equivalent in the cases we looked at so far, make slightly different predictions in general:

- The shorter than ... high = LITTLE-er long than. . high analysis (our original proposal) has the degree negation sit in the main clause, with the comparative.

- The shorter than... high = MORE short than... LITTLE high analysis (the alternative from Section 5) has the degree negation sit with the adjective in the than-clause.

If we could find a scope-taking element that generally takes scope between the A in the than-clause and the comparative operator, we should be able to tease the two apart. It turns out that modal verbs fit this description. Setting up the relevant examples in a way that allows reliable judgements, though, requires some work, as we will see. I will discuss two classes of examples, one with universal modals, one with existential modals.

\subsection{Universal Modals}

For starters, we observe that the modal have to takes scope within the than clause, hence below the comparative MORE: ${ }^{7}$

\footnotetext{
ation:

${ }^{7}$ The two readings are more formally represented in (i); @ stands for the matrix world of evalu-
} 
The ladder is longer than it has to be.

a. the ladder's length is more than the length that it has in every permitted world

'the ladder is longer than the minimum required length'

b. * for every permitted word, the ladder's length is more than its length in that world

'the ladder is longer than the maximum permitted length'

A plausible LF for such an example is (28): ${ }^{8}$

[ more [ $\lambda d$ than HAS-TO the ladder be $d$-long ] [ $\lambda d$ the ladder is $d$-long ]]

Having established this, our test case is exemplified by (29):

(29) Unfortunately, the existing drawbridge is shorter than the new moat has to be wide.

I think (29) appropriately describes the following scenario: I recently 'acquired' a new castle, and, as its law-abiding new owner, I want to make sure that it complies with the existing municipal regulations. It turns out that a recently amendment passed no doubt to prevent the very sort of acquisition I just made - requires the moat of castles like mine to be of a certain minimum width, say, $30 \mathrm{ft}$, whereas the existing moat is only $15 \mathrm{ft}$ wide. I will have to have my moat widened to at least $30 \mathrm{ft}$, but unfortunately, the existing drawbridge is only $15 \mathrm{ft}$ long. I will therefore also have to replace the drawbridge with a longer one, or build a $15 \mathrm{ft}$ dock into the moat where the bridge is (cf. figure 4).

On the first analysis proposed, (29) has the LF in (30), yielding the interpretation in (31):

(30) [ LITTLE-more [ $\lambda d$ than MUST the new moat be $d$-wide ] [ $\lambda d$ [ the ladder is $d$-long ] ] ]

(i) $\quad$ a. $\quad\left\{d \mid d \leq L E N G T H_{@}(\right.$ ladder $\left.)\right\} \supset\left\{d \mid \forall w \in \operatorname{Deon}(@)\left[d \leq \operatorname{LENGTH}_{w}(\right.\right.$ ladder $\left.\left.)\right]\right\}$

b. $\quad * \forall w \in \operatorname{Deon}(@)\left[\left\{d \mid d \leq L E N G T H_{@}(\right.\right.$ ladder $\left.)\right\} \supset\left\{d \mid L E N G T H_{w}\right.$ (ladder) $\left.\}\right]$

${ }^{8}$ One might think that it goes without saying that the modal scopes below the comparative operator, rather than above it. However, as observed e.g. in Schwarzschild and Wilkinson (2002) and discussed there as well as in Heim (2006b), nominal quantifiers as well as other universal modals yield exactly the other reading:

(i) a. The ladder is longer than it should/ought to be.

b. This ladder is longer than every other ladder in our catalogue.

Clearly, these expression are useless as probes into scope relations between -er and anything within the than-clause, then. At least need to, be required to, be necessary and arguably must pattern with have to, though. 


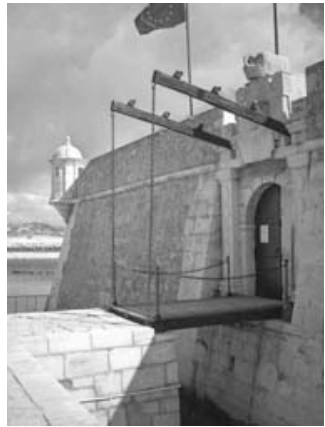

Figure 4: The existing drawbridge was shorter than the new moat had to be wide.

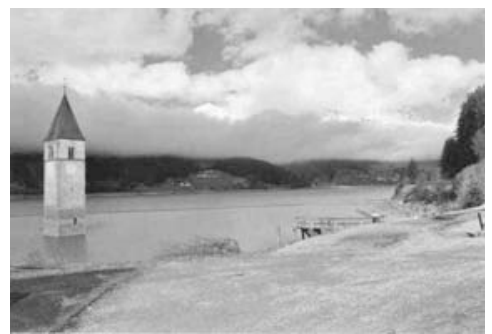

Figure 5: The new reservoir is less deep than church towers were allowed to be tall.

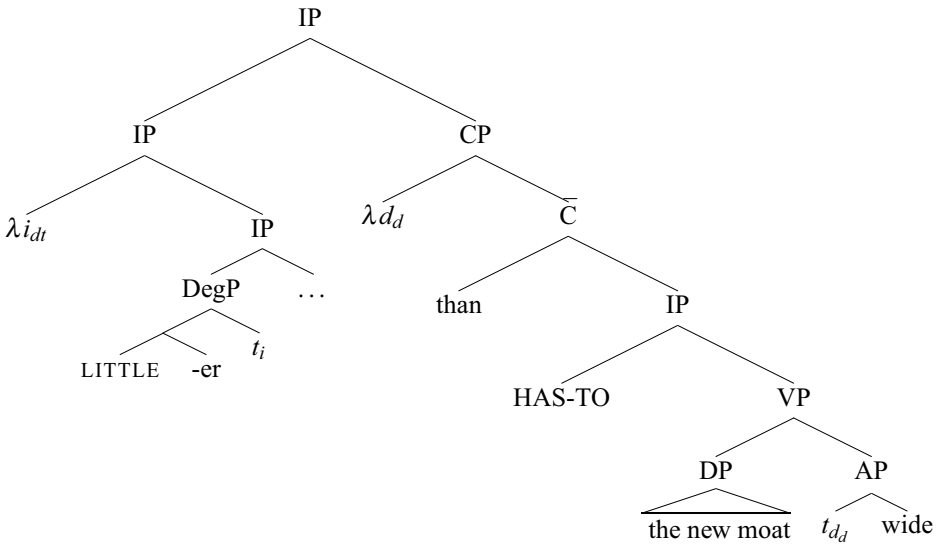

$\left\{d \mid \forall w \in \operatorname{Deon}(@)\left[d \leq\right.\right.$ WIDTH $_{w}($ moat $\left.\left.)\right]\right\} \supset\left\{d \mid d \leq L E N G T H_{@}(\right.$ drawbrigde $\left.)\right\}$ 'the minimum required width of the moat is more than the actual length of the drawbridge'

What happens here is that HAS-TO gets to scope over the positive A wide. Accordingly, the than-clause denotes the set of degrees to which the moat is wide in all of the permitted worlds, which is its the interval measuring its width in those worlds in which it is the least wide (its minimum required width). ${ }^{9}$ LITTLE-er than inverts that to the negative measurement of the moat's width (its 'narrowness') in the world(s) in which it's the narrowest (its 'maximum permitted narrowness').

It is then claimed that that negative measurement is less than the negative interval measuring the drawbridge's length (its 'shortness'), i.e. the bridge's shortness

\footnotetext{
${ }^{9}$ Recall that $\mathrm{A}^{+} \mathrm{s}$ like wide are 'monotonous': if in any $w$ the drawbridge is $5 \mathrm{ft}$. wide, it is also $4 \mathrm{ft}$., $3 \mathrm{ft}$. etc. wide in $w$.
} 
is bigger than the maximum permitted narrowness of the moat (it's narrowness in those worlds among the permitted ones in which it is the narrowest). This is equivalent to saying the bridge is less long than the moat is wide in its narrowest possible incarnation. It follows that we can't build a moat that the existing drawbridge will span. This is indeed what (29) intuitively means, and implies, respectively.

The alternative analysis gives (29) the LF in (32), resulting in the interpretation in (33):

(32) [ more [ $\lambda d$ than HAS-TO the new moat be $d$-LitTLE-wide ] [ $\lambda d$ [ the drawbridge is $d$-LITTLE-long ] ] ]

$$
\begin{aligned}
& \left\{d \mid \forall w \in \text { Deon }(@)\left[\text { WIDTH }_{w}(\text { moat })<d\right]\right\} \subset\left\{d \mid \text { LENGT }_{w}(\text { drawbridge })<\right. \\
& d\} \\
& \text { 'the minimum required narrowness of the moat is less than the actual short- } \\
& \text { ness of the drawbridge' } \\
& \text { 'the maximum allowed width of the moat is more than the length of the } \\
& \text { drawbridge' }
\end{aligned}
$$

Here, HAS-TO scopes over the $\mathrm{A}^{-}$narrow/LITTLE wide in the than-clause. As a result, we get from the entire than-clause the smallest negative degree that measures the moat's 'narrowness' across permitted worlds (its 'minimum required narrowness'). Note that this is crucially different from what we got above (the moat's 'maximum permitted narrowness'). It is now claimed again that this is a proper subset of the drawbridge's 'shortness', which means the drawbridge is shorter than the moats widest ('least narrow') permitted incarnation. From this it would follow that we can (but don't have to) build a moat that the drawbridge won't span. As best as I can tell, (29) does not imply that at all, and has no such reading. I conclude that (30) correctly captures the truth conditions of (29), while (32) does not, giving us grounds to prefer the initial analysis from Section 3 to the alternative sketched in Section 5.

I believe one can get the same sense from examples with comparative deletion: there is a scopal difference between less $A+$ than... have to... and more $A$ than ... have to ... (though for some speakers, (35) is actually ambiguous between the paraphrases given in (34) and (35), a fact I discuss in Büring 2007)):

(34) The new drawbridge is less wide than the coaches have to be

'the coaches have to be wider than the drawbridge is (so no coach can cross the bridge)'

(35) The new drawbridge is narrower than the coaches have to be narrow. 'the coaches can be wider than the drawbridge is (so some coaches might not be able to cross the bridge)'

Using these two as our standard of comparison, I submit that the meaning of (36) is parallel to the less $A^{+}$-comparative in (34) (as predicted by our official proposal), rather than the more $A^{-}$-comparative in (35) (as predicted by the alternative):

(36) The new drawbridge is narrower than the coaches have to be long. 
'the coaches have to be longer than the drawbridge is (so no coach can cross the bridge sideways)'

In the following subsection, I repeat the same argument with existential modals. The conclusion will be the same.

\subsection{Existential Modals}

Allowed, just like have to scopes below the comparative: ${ }^{10}$

(37) The ladder is longer than it is allowed to be.

a. the ladder's length is more than the length that it has in any permitted world 'the ladder is longer than the maximum permitted length'

b. * for some permitted word, the ladder's length is more than its length in that world

'the ladder is longer than the minimum required length'

An example to test cross-polar nomalies with existential modals is provided in (38):

(38) Thank Odin! The moat around our new castle is narrower than drawbridges are allowed to be long around here.

'the width of the moat is less than the maximum permitted length of drawbridges (so we can get one that spans it)'

I might utter (38) if I am in the habit of flipping castles. I recently acquired, at a bargain price, a somewhat desolate castle with a moat but no drawbridge. My plan was fix the castle up, add a drawbridge, and sell it with a considerable profit. Suddenly it dawned on me that the reason for the low price of my castle might have been that local draw bridge codes don't allow bridges long enough to span my moat (truth be told, they are an eye-sore), and that I was conned into acquiring a castle that cannot be legally accessed by bridge, and is hence practically worthless. To my relief, I find that that is not the case, and belt out (38).

That is, (38) is true if the width of the moat is less than the maximum permitted length of bridges (the 'minimum permitted shortness'), not, as the alternative would have it, its minimum permitted length ('maximum permitted shortness')

The same point can be made with (39), which I believe accurately describes figure 5:

(39) The new reservoir is less deep than church towers were allowed to be tall (so some of them are still visible).

Again, we can observe the same effect with comparative deletion:

(40) The new bridge is less wide than coaches are allowed to be (so some

\footnotetext{
${ }^{10}$ As do be possible, can, could, contrasting only with might, see the references in note 8 .
} 
of them won't fit).

(41) The new bridge is narrower than coaches are allowed to be narrow (so none of them will fit).

(42) The new bridge is narrower than coaches are allowed to be long (so some of them won't fit sideways).

\section{Summary}

In this paper I have drawn attention to a circumscribed class of cross-polar nomalies that seem to be counter-examples to the generalization that one can't compare a positive A with a negative A. I have argued that cross-polar nomalies are possible because MORE LITTLE- $A$ in the main clause can be re-interpreted as LITTLE-er $A$.

The reason we don't see the same in regular cross-polar anomalies is syntactic: it is preferred to delete LITTLE $A$, i.e. do comparative deletion (and interpret the comparative regularly).

I have shown that an equivalent result could be achieved in simple cases by assuming that MORE LITTLE- $A$ can license deletion of LITTLE in the than-clause. However, cases involving modals in the than-clause seem to favor the former analysis.

\section{References}

Bierwisch, Manfred (1989). "The Semantics of Gradation.” In Manfred Bierwisch and Ewald Lang, eds., Dimensional Adjectives, 71-262. Berlin: SpringerVerlag.

Büring, Daniel (2004). "Crossover Situations." Natural Language Semantics 12(1):23-62.

Büring, Daniel (2005). Binding Theory. Cambridge Textbooks in Linguistics. Cambridge: Cambridge University Press.

Büring, Daniel (2007). "More Or Less." In Paper presented at the Chicago Linguistic Society meeting. Chicago.

Faller, Martina (1998). "A Vector Space Semantics for Comparatives.” Ms., Stanford University.

Hale, Austin (1970). "Conditions on English Comparative Clause Pairings." In R. Jacobs and P. Rosenbaum, eds., Readings in English Transformational Grammar, 30-55. Washington: Georgetown University Press.

Heim, Irene (2006a). "Little." In Proceedings of SALT XVI.

Heim, Irene (2006b). "Remarks on Comparative Clauses as Generalized Quantifiers." Manuscript, MIT .

Kennedy, Christopher (2001). "Polar Opposition and the Ontology of 'Degrees'." LP 24:33-70. 
Rullmann, Hotze (1995). Maximality in the Semantics of Wh-Constructions. Ph.D. thesis, University of Massachusetts, Amherst.

Schwarzschild, Roger and Karina Wilkinson (2002). "Quantifiers in comparatives: A semantics of degree based on intervals." Natural Language Semantics $10: 1-41$.

Seuren, P.A.M. (1978). "The Structure and Selection of Positive and Negative Gradable Adjectives." In W.M. Jacobsen Farkas, Donka and K.W. Todrys, eds., Papers from the Parasession on the Lexicon, Chicago Linguistics Society, 336-346. Chicago: Chicago Linguistic Society.

Seuren, Pieter A.M. (1984). "The Comparative Revisited.” Journal of Semantics 3:109-141.

von Stechow, Arnim (1984). "My Reaction to Cresswell's, Hellan's, Hoeksema's, and Seuren's Comments." Journal of Semantics 3:183-199.

Takahashi, Shoichi and Danny Fox (2005). "Max Elide and the Re-Binding Problem.” In Proceedings of SALT XV.

\section{Sources of the Figures}

Figure 1 (ladder\&house): The Whatever Page (http://www.skitchin.net/rant/rant.html)

Figure 2 (boat with dinghy): Whitehall Rowing and Sailing (http://www.whitehallrow.com/rowboats/minto_9_sail.php)

Figure 3 (boat stuck in rocks): Sailing Anarchy (http://www.sailinganarchy.com/editor/2006/edword_august2006.htm)

Figure 4 (drawbridge): Georges Jansoone: Entrance with drawbridge; Forte da Ponta da Bandeira; Lagos, Portugal 2006. Wikimedia Commons.

Figure 5 (flooded village): Leon Brunken and Mark Verhappen: Flooded Village in Lago di Resia. Edelweiss 3 Tour (http://www.geocities.com/leonb65535/bike/edelweiss3/edelweiss3.html) 